\title{
Genetic implications of a biological invasion: Chromosomal and DNA barcode monomorphism in Old World populations of Colorado potato beetle Leptinotarsa decemlineata (Coleoptera: Chrysomelidae)
}

\author{
GAYANe KARAGYAN $^{1}$ (D), VladimiR LUKHTANOV ${ }^{2}$ iD, MERI MAZMANYAN ${ }^{1}$, ILONA STEPANYAN 1 , TIGRAN GHREJYAN ${ }^{1}$ (D), \\ Alena ABAKUMOVA ${ }^{3}$ and Oxana NESTEROVA ${ }^{3}$ (D) \\ ${ }^{1}$ Scientific Center of Zoology and Hydroecology, NAS RA, P. Sevak 7, Yerevan 0014, Armenia; \\ e-mails: gaykaragyan@yahoo.com, meriliv33@gmail.com, ilonastepanyan37@gmail.com, tkredjyan@gmail.com \\ ${ }^{2}$ Zoological Institute of Russian Academy of Sciences, Universitetskaya nab. 1, St. Petersburg 199034, Russia; \\ e-mail: lukhtanov@mail.ru \\ ${ }^{3}$ Belarusian State University, Faculty of Biology, Kurchatova 10, Minsk 220045, Belarus; e-mails: helen.a.2013@mail.ru, \\ oxanesterova@gmail.com
}

Key words. Coleoptera, Chrysomelidae, Leptinotarsa decemlineata, Colorado potato beetle, invasion, Old World, chromosome, COI, DNA barcoding, taxonomy

\begin{abstract}
Once introduced into new area, invasive species can be expected to have low genetic diversity due to the founder effect. Here we tested this prediction using cytogenetic and molecular analysis of Armenian and Belarusian populations of Colorado potato beetle Leptinotarsa decemlineata (Say, 1824) and by comparing the results with those of native (North America) and those introduced into Europe. This revealed that the karyotype of males from Armenia and Belarus is remarkably conserved with $2 n=35$ $(34+X 0), n=17 A A+X 0$; and includes a pair of large acrocentric chromosomes. Thus, these populations belong to the so-called acrocentric chromosome race of the Colorado potato beetle. At diakinesis there are clearly visible argentophilic signals, probably NORs (the nucleolus organizer regions) present on some autosomal bivalents, while the $\mathrm{X}$ chromosome was homogenously argentophilic during different stages of meiosis. C-banding revealed a small amount of constitutive heterochromatin weakly visible in the pericentromeric regions of some chromosomes. Analysis of the DNA-barcode fragment of the gene cytochrome c oxidase subunit I $(\mathrm{COI})$ revealed a single haplotype (we call it "the European haplotype") and lack of inter-population variability in all the samples collected from different locations in Armenia and Belarus. The comparison of our karyological and molecular data with that available in the literature and GenBank shows that all the populations studied from the Old World are monomorphic with respect to karyotype and the mitochondrial DNA-barcode. We assume that (1) the presence of acrocentric chromosomes in the karyotype and (2) the European haplotype of mitochondrial genome are the ancestral states for all populations in the Old World and inherited from the New World invaders who colonized Europe 100 years ago. New World populations are polymorphic with respect to karyotype and mitochondrial genes; however, the European haplotype has not yet been found in America. We believe that in the future it will be found in North America, which will shed light on the origin of populations of this dangerous pest in Eurasia.
\end{abstract}

\section{INTRODUCTION}

Colorado potato beetle Leptinotarsa decemlineata (Say, $1824)$ is one of the best known invasive insect species. Despite significant progress in plant protection, Colorado potato beetle (CPB) is still the main pest of potato (Solanum tuberosum) worldwide. However, the beetles may damage tomatoes (Solanum lycopersicum), eggplant (Solanum melongena) and tobacco (Nicotiana tabacum), as well as feed and survive on the other plants of the family Solanaceae (Alyokhin, 2009; Liu et al., 2012).

CPB spread across the United States and Canada during the second half of the 19th century and then invaded Europe at the beginning of the 20th century (France, Bordeaux) and is currently present almost throughout the Eur- asian continent as far as China in Asia (De Wilde \& Hsiao, 1981; Jolivet, 1991; Capinera, 2001; Udalov \& Benkovskaya, 2011). Within the former Soviet Union, this species was first recorded in Byelorussian SSR in 1947 (Markovets, 1950) and in Armenian SSR - in 1976 (Nalbandyan, 1984).

CPB is highly fecund, highly intraspecifically polymorphic, ecologically plastic and adaptable, and quick to develop resistance to insecticides, which enables it to successfully adapt to different environmental factors (Ushatinskaya, 1981; Udalov \& Benkovskaya, 2011).

CPB is well studied with respect to morphology, phenotypic structure, life-cycle, ecology, distribution and behaviour (for references, see Fasulati, 1993; Boiteau, 1994; 
Udalov \& Benkovskaya, 2011; Brechko et al., 2016). However, there are not many cytogenetic and molecular studies on L. decemlineata.

The karyotype of L. decemlineata (as Doryphora decemlineata) was first described by Stevens (1906) and the male chromosome number was misinterpreted as $2 \mathrm{n}=36$ (34 + $\mathrm{XY})$. Further karyological studies showed that the diploid chromosome number of this species is $2 \mathrm{n}=35(34+\mathrm{X} 0)$ in the male and $2 n=36(34+X X)$ in the female, with a large submetacentric $\mathrm{X}$ chromosome and mostly submetacentric autosomes (Guénin \& Scherler, 1951; Smith, 1953; Hsiao \& Hsiao, 1982, 1983; Hsiao, 1985; Petitpierre et al., 1988).

More recent studies report the first data obtained using C-banding staining and in situ restriction enzyme digestion combined with the analysis of repetitive DNA for studying the organization of heterochromatin in chromosomes of $L$. decemlineata (Baus Lončar et al., 2005). Repetitive DNA in nuclear DNA of CPB and pericentromerically located small heterochromatic blocks on all chromosomes in its karyotype. The chromosome location of two different satellite-DNA families on mitotic and meiotic chromosomes of $L$. decemlineata was studied by fluorescence in situ hybridization using LEDE-I and LEDE-II satellite DNAs as probes (Lorite et al., 2013). Positive hybridization signals in the pericentromeric region on some chromosomes, including $\mathrm{X}$ chromosome, is recorded.

There are several studies on CPB populations that used molecular markers (Jacobson \& Hsiao, 1983; AzeredoEspin et al., 1991, 1996; Zehnder et al., 1992; Sidorenko et al., 2000; Hawthorne, 2001; Sidorenko \& Berezovska, 2002; Grapputo et al., 2005; Grapputo, 2006; Lorite et al., 2013; Zhang et al., 2013; Przybylska et al., 2014; Izzo et al., 2018; Yang et al., 2020), including analyses based on sequencing the whole genome (Crossley et al., 2017; Cohen et al., 2021). These methods are promising for the investigation of intra- and interpopulation polymorphism, as well as migration routes and microevolutionary processes accompanying the formation of the current CPB range (Udalov \& Benkovskaya, 2011). Nonetheless, currently there is little data on mitochondrial DNA barcodes, the standardized gene regions (658 bp long, 5' segment of mitochondrial cytochrome oxidase subunit I, COI) in GenBank (Table 2). This is strange, since over the past 15 years, DNA barcodes have become a universal tool not only for identifying species (Hebert et al., 2003), but also for understanding the evolution and ecology of biodiversity (Kress et al., 2015).

The aim of this study was to reveal possible similarities or differences between Armenian and Belarusian populations of Colorado potato beetle based on karyological and DNA barcode data. In addition, we were interested in testing the prediction that due to the founder effect (Barton \& Charlesworth, 1984), invasive populations have a lower genetic diversity than native populations of the same species (Dlugosch \& Parker, 2008; Holm et al., 2018; but see also: Roman \& Darling, 2007). To test this prediction, a chromosomal and DNA barcode comparison of native (North America) and introduced (Europe) populations of CPB was carried out.

\section{MATERIAL AND METHODS}

\section{Material and sampling}

Adults of Leptinotarsa decemlineata were collected in Armenia and Belarus in 2019 (Table 1) on Solanum tuberosum. For the karyological study male and female abdomens were dissected, immersed in $0.9 \%$ sodium citrate solution at room temperature for $40 \mathrm{~min}$. Then the gonads were fixed in 3:1 fixative $(96 \%$ ethanol: glacial acetic acid). The remaining bodies of the same specimens were fixed in $96 \%$ ethanol for DNA study. The fixed samples were frozen and stored at $-20^{\circ} \mathrm{C}$ until processed.

\section{Preparation of karyological slides}

The dissected gonads were placed on slides in a drop of $70 \%$ acetic acid. Squashed chromosomal preparations were obtained using the dry ice quick-freezing technique (Conger \& Fairchild, 1953).

Ag-banding was done according to the method proposed by Howell \& Black (1980), with minor modifications. The slides were exposed to hydrolysis in $2 \mathrm{~N}$ formic acid for $10 \mathrm{~min}$, rinsed in running water and dried. Then $4-5$ drops of $50 \%$ aqueous silver nitrate $\left(\mathrm{AgNO}_{3}\right)$ solution and 2 drops of colloidal developer solution $(0.2 \mathrm{~g}$ gelatin, $10 \mathrm{ml}$ distilled water and $0.1 \mathrm{ml}$ concen-

Table 1. Specimens of Leptinotarsa decemlineata used in the chromosome and DNA-barcode analyses.

\begin{tabular}{|c|c|c|c|c|}
\hline NN & Locality & $\begin{array}{l}\text { Date of } \\
\text { collection }\end{array}$ & $\begin{array}{c}\text { Karyologically } \\
\text { examined specimens }\end{array}$ & $\begin{array}{l}\text { DNA examined } \\
\text { specimens }\end{array}$ \\
\hline 1. & Armenia, Armavir Prov. env. Arshaluys vill. & 13.06 .2019 & $15 \hat{\jmath}, 19 q$ & 1 \\
\hline 2. & Armenia, Kotayk Prov., env. Aghavnadzor vill. & 18.07.2019 & $3 \hat{\jmath}, 3+$ & 1 \\
\hline 3. & Armenia, Lori Prov., env. Hartagyugh vill. & 6.08.2019 & $4 \hat{\jmath}, 4 \bigcirc$ & 1 \\
\hline 4. & Armenia, Gegharkunik Prov., env. Chambarak vill. & 11.07.2019 & $4 \hat{\jmath}, 3$ 우 & 1 \\
\hline 5. & Belarus, Vitebsk Reg., Vitebsk District, Pushkari vill. & 30.07 .2019 & $2 \hat{\jmath}, 29$ & 1 \\
\hline 6. & Belarus, Vitebsk Reg., Polotsk District, env. Polotsk city & 31.07.2019 & $2 \hat{\jmath}, 20$ & 1 \\
\hline 7. & Belarus, Grodno Reg., Ashmyany District, Zhuprany vill. & 10.08.2019 & $3 \hat{\jmath}, 1$ 우 & 1 \\
\hline 8. & Belarus, Gomel Reg., Svietlahorsk District, Rakshin vill. & 19.07.2019 & $1 \hat{\delta}, 3$ 우 & 1 \\
\hline 9. & Belarus, Vitebsk Reg., Orsha District, Krapivno vill. & 29.07.2019 & $3 \hat{\jmath}, 1$ 우 & 1 \\
\hline 10. & Belarus, Vitebsk Reg., Vitebsk District, env. Tulovo town & 30.07 .2019 & $1 \hat{\jmath}, 3$ + & - \\
\hline 11. & Belarus, Brest Reg., Zhabinka District, env. Zhabinka city & 8.07.2019 & $1 \hat{\jmath}, 3$ + & - \\
\hline 12. & Belarus, Gomel Reg., Kalinkavichy District, env. Kalinkavichy town & 17.07.2019 & $1 \hat{0}, 3+$ & - \\
\hline 13. & Belarus, Brest Reg., Luninets District, env. Luninets town & 14.07.2019 & $30^{\lambda}, 1+$ & - \\
\hline 14. & Belarus, Mogilev Reg., Mogilev District; Kuty vill. & 23.07.2019 & $30^{\lambda}, 1$ 우 & - \\
\hline 15. & Belarus, Mogilev Reg., Babruysk District, Telusha vill. & 24.07.2019 & $3 \hat{\jmath}, 1+$ & - \\
\hline 16. & Belarus, Minsk Reg., Minsk District, Shchomyslitsa vill. & 3.06.2019 & $4+$ & - \\
\hline
\end{tabular}


Table 2. Specimens of the Leptinotarsa used in the DNA-barcode analysis.

\begin{tabular}{|c|c|c|c|c|c|}
\hline Species & Specimen voucher & $\begin{array}{c}\text { GenBank } \\
\text { accession no. }\end{array}$ & Country & Locality & Reference \\
\hline L. decemlineata & SCZHE-19-001 & MW346685 & Armenia & Armavir Prov., env. Arshaluys vill & This study \\
\hline L. decemlineata & SCZHE-19-002 & MW346681 & Armenia & Kotayk Prov., env. Aghavnadzor vill. & This study \\
\hline L. decemlineata & SCZHE-19-003 & MW346686 & Armenia & Lori Prov., env. Hartagyugh vill. & This study \\
\hline L. decemlineata & SCZHE-19-004 & MW346683 & Armenia & Gegharkunik Prov., env. Chambarak vill. & This study \\
\hline L. decemlineata & SCZHE-19-140 & MW346682 & Belarus & Vitebsk Reg., Vitebsk District, Pushkari vill. & This study \\
\hline L. decemlineata & SCZHE-19-141 & MW346684 & Belarus & Vitebsk Reg., Polotsk District, env. Polotsk city & This study \\
\hline L. decemlineata & SCZHE-19-194 & MW348766 & Belarus & Grodno Reg., Ashmyany District, Zhuprany vill. & This study \\
\hline L. decemlineata & SCZHE-19-075 & MW348765 & Belarus & Gomel Reg., Svietlahorsk District, Rakshin vill. & This study \\
\hline L. decemlineata & SCZHE-19-127 & MW348764 & Belarus & Vitebsk Reg., Orsha District, Krapivno vill. & This study \\
\hline L. decemlineata & USDABRL Roehrdanz 1868 & HQ605769 & USA & Fargo, ND & Yocum et al., 2011 \\
\hline L. decemlineata & USDABRL Roehrdanz 1313 & HQ605768 & USA & MD & Yocum et al., 2011 \\
\hline L. decemlineata & BIOUG<CAN>:AY165708 & AY165708 & Canada & Ontario, Wellington County, Puslinch Township & Hebert et al., 2003 \\
\hline L. decemlineata & - & XM_023169376 & USA & Long Island New York & GenBank \\
\hline L. decemlineata & ZFMK-TIS-5917 & KU915233 & Germany & Thuringia, Eisenach, Wilhelmsthal, Fischteiche & Rulik et al., 2017 \\
\hline L. decemlineata & ZFMK-TIS-2000691 & KU914658 & Poland & $\begin{array}{l}\text { Woiwodschaft Westpommern, Powiat Slawienski, } \\
\text { Landg, Campingplatz Wicie }\end{array}$ & Rulik et al., 2017 \\
\hline L. decemlineata & ZFMK-TIS-2003262 & KU911127 & Germany & $\begin{array}{l}\text { Saxony-Anhalt, Halberstadt, } \\
\text { Landkreis Harz, Athenstedt }\end{array}$ & Rulik et al., 2017 \\
\hline L. decemlineata & ZFMK-TIS-2000692 & KU909921 & Poland & $\begin{array}{l}\text { Woiwodschaft Westpommern, Powiat Slawienski, } \\
\text { Landg, Campingplatz Wicie }\end{array}$ & Rulik et al., 2017 \\
\hline L. decemlineata & ZFMK-TIS-2003261 & KU907193 & Germany & $\begin{array}{l}\text { Saxony-Anhalt, Halberstadt, } \\
\text { Landkreis Harz, Athenstedt }\end{array}$ & Rulik et al., 2017 \\
\hline L. decemlineata & GBOL_Col_FK_8406 & KM439182 & Germany & $\begin{array}{l}\text { North Rhine-Westphalia, Niederrheinische Bucht, } \\
\text { Rhein-Sieg, Bornheim-Hemmerich, Ortslage }\end{array}$ & Hendrich et al., 2015 \\
\hline L. decemlineata & BFB_Col_FK_10263 & KM439498 & Austria & $\begin{array}{l}\text { Burgenland, Neusiedlersee, Neusiedl am See, } \\
\text { Illmitz, Biologische Station }\end{array}$ & Hendrich et al., 2015 \\
\hline L. decemlineata & GBOL_Col_FK_8725 & KM439249 & Germany & $\begin{array}{l}\text { Baden-Wuerttemberg, Suedliches-Oberrhein-Tiefl, } \\
\text { Breisgau-Hochschwarzwald, Boetzingen, Ortslage }\end{array}$ & Hendrich et al., 2015 \\
\hline L. decemlineata & BC ZSM COL 02288 & JF889843 & Germany & $\begin{array}{l}\text { North Rhine-Westphalia, Niederrheinische Bucht, } \\
\text { Rhein-Sieg, Bornheim-Hemmerich, Ortslage }\end{array}$ & GenBank, iBOL \\
\hline
\end{tabular}

L. decemlineata O.V.Sukhorukova 296 (LBIA) DQ649100 Russia Bashkortostan, Beloreckiy, Mezhgorie

L. decemlineata O.V.Sukhorukova 306 (LBIA) DQ649101 Russia Bashkortostan, Beloreckiy, Mezhgorie

L. decemlineata M.B. Udalov 23 (LBIA) DQ649098 Russia Bashkortostan, Ufimskiy, Dmitrievka

L. decemlineata M.B. Udalov 607 (LBIA) DQ649097 Russia Bashkortostan, Fedorovskiy, Dedovo

L. decemlineata M.B.Udalov 379 (LBIA) DQ649096 Russia Bashkortostan, Fedorovskiy, Dedovo

L. decemlineata M.B.Udalov 14 (LBIA) DQ649099 Russia Bashkortostan, Ufimskiy, Dmitrievka

L. decemlineata M.B. Udalov 35 (LBIA) DQ127906 Russia Bashkortostan, Ufimskiy; Dmitrievka

L. decemlineata R.A. llyasov 332 (LBIA) DQ649095 Russia Bashkortostan, Tatyshlinskiy, Schulganovo



L. decemlineata M.B. Udalov 421 (LBIA) DQ127909 Russia Bashkortostan, Fedorovskiy; Dedovo

L. decemlineata O.V. Sukhorukova 305 (LBIA) DQ127907 Russia Bashkortostan, Beloreckiy; Mezhgorie

L. decemlineata Yu.M.Nikonorov 923 (LBIA) DQ011111 Russia Bashkortostan, Miyakinskiy, Kirgiz-Miyaki

L. decemlineata M.B. Udalov 363 (LBIA) DQ127908 Russia Bashkortostan, Tatyshlinskiy; Schulganovo

L. decemlineata BCZSM_COLA_1040 KM448111 Austria Burgenland

L. haldemani BIOUG<CAN>:09BBCOL-0248 HM433598 USA Oklahoma, Marshall Co., UOBS, near Lake Texoma

Oklahoma, Marshall Co., UOBS,

$\begin{array}{lcccc}\text { L. haldemani } & \text { BIOUGCAN:09BBCOL-0247 } & \text { HM433597 } & \text { USA } & \begin{array}{c}\text { Oklahoma, Marshall Co., UO } \\ \text { near Lake Texoma }\end{array} \\ \text { L. haldemani } & - & \text { DQ459377 } & \text { USA } & \text { AZ, Benson }\end{array}$

L. haldemani BIOUG<CAN>:10BBCOL-0771 HQ984330 USA Texas, Caverns of Sonora Nature Trail

$\begin{array}{lllll}\text { L. juncta } & \text { BMNH:704381 UC255422 USA W, Randolph Co., Elkwater }\end{array}$

L. juncta

L. juncta

L. texana

L. texana

L. texana

L. texana

USDABRL Roehrdanz FPB-A HQ605770 USA

USDABRL Roehrdanz 2181SB HQ605771 USA

USDABRL Roehrdanz 1914 HQ605774 USA WWAI ww21931

USDABRL Roehrdanz 1915 WWAI ww21948
MK288007 Sth Africa

HQ605775 USA MK288008 Sth Africa
Udalov \& Benkovskaya, 2010 Udalov \& Benkovskaya, 2010 Udalov \& Benkovskaya, 2010 Udalov \& Benkovskaya, 2010 Udalov \& Benkovskaya, 2010 Udalov \& Benkovskaya, 2010 Udalov \& Benkovskaya, 2010 Udalov \& Benkovskaya, 2010 Udalov \& Benkovskaya, 2010 Udalov \& Benkovskaya, 2010 Udalov \& Benkovskaya, 2010 Udalov \& Benkovskaya, 2010 Udalov \& Benkovskaya, 2010

Hendrich et al., 2015

GenBank, iBOL

GenBank, iBOL

Greenstone et al., 2007

GenBank, iBOL

Nie et al., 2018

Yocum et al., 2011

Yocum et al., 2011

Yocum et al., 2011 GenBank

Yocum et al., 2011 GenBank trated formic acid - $\mathrm{HCOOH}$ ) were placed on each slide. The slides were covered with a coverslip and incubated on a hotplate for 3-4 min at $60^{\circ} \mathrm{C}$ in a moist chamber (warmed beforehand). The slides were dried after rinsing in distilled water.

C-banding was revealed using the protocol of Rożek (2000). The slides were treated for $1-3 \mathrm{~min}$ in $0.2 \mathrm{~N} \mathrm{HCL}$ at room temperature then rinsed in distilled water. Thereafter, the slides were placed in $5 \% \mathrm{Ba}(\mathrm{OH})_{2}$, solution at $20^{\circ} \mathrm{C}$ for approximately 4 min, then rinsed with distilled water. Then the slides were incubated in $2 \times \mathrm{SSC}$ solution $(0.3 \mathrm{M}$ sodium chloride containing $0.03 \mathrm{M}$ trisodium citrate) at $60^{\circ} \mathrm{C}$ for $1 \mathrm{~h}$. After rinsing in distilled water, the slides were dried and stained using $4 \%$ Giemsa solution in phosphate buffer (pH 6.8) for $8 \mathrm{~min}$. 

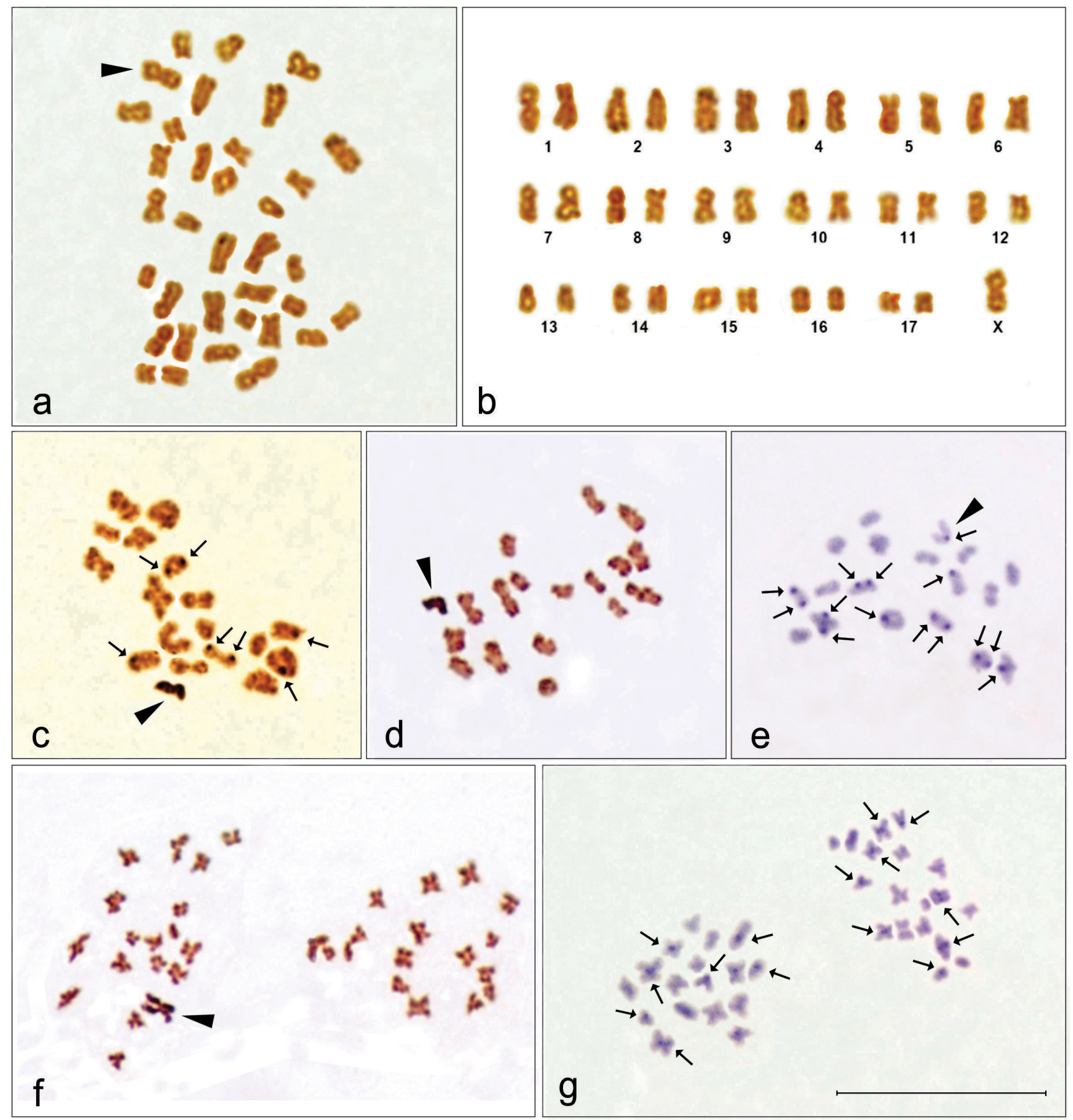

Fig. 1. Karyotype of males of Leptinotarsa decemlineata from Armenian populations. a - mitotic metaphase; $b$ - karyogram; c-diakinesis; $\mathrm{d}, \mathrm{e}$ - prometaphase I; $\mathrm{f}, \mathrm{g}$ - metaphase II. Arrowheads indicate X sex chromosome. c - Ag-banding, arrows indicate argentophilic signals (NORs); e, g-C-banding, arrows indicate C-blocks. Bar equals $10 \mu \mathrm{m}$.

\section{DNA extraction, PCR amplification and sequencing}

Total DNA was extracted from the wing muscle, using the Qiagen DNeasy Blood \& Tissue Kit (QIAGEN, Hilden, Germany) following the protocol for Animal Tissue.

Amplification of a fragment of the COI gene was done using PCR and the following pair of primers (Folmer et al., 1994): LCO1490 5'-GGTCAACAAATCATAAAGATATTGG-3' and HCO2198 5'-TAAACTTCAGGGTGACCAAAAAATCA-3'.

PCR was performed in a $25 \mu \mathrm{l}$ reaction volume using $2.5 \mu \mathrm{M}$ $\mathrm{MgCl}_{2}, 1.2 \mu \mathrm{BSA}$ (concentration $1 \mathrm{mg} / \mathrm{ml}$ ), $0.8 \mu \mathrm{M}$ GeneAmp dNTPs Mix (Applied Biosystems, Beverly, MA, USA), $0.6 \mu \mathrm{M}$ of each primer, $2.5 \mu \mathrm{l} 1 \times$ PCR buffer II (Applied Biosystems), 1
U of ABI AmpliTaq DNA Polymerase (Applied Biosystems) and $3 \mu \mathrm{l}$ of the respective genomic DNA extract.

PCR conditions for $C O I$ amplification were as follows: initial denaturation period of 2 min at $94^{\circ} \mathrm{C}$ was followed by 30 cycles of $1 \mathrm{~min}$ at $94^{\circ} \mathrm{C}$, annealing for $30 \mathrm{~s}$ at $45^{\circ} \mathrm{C}$ and extension for 1 min $30 \mathrm{~s}$ at $72^{\circ} \mathrm{C}$, with a final extension step of $10 \mathrm{~min}$ at $72^{\circ} \mathrm{C}$.

PCR products were purified with ExoStar (GE Healthcare, Little Chalfont, UK) in accordance with the manufacturer's manual and sequenced in both directions externally by StarSEQ GmbH (Mainz, Germany).

DNA extraction, PCR amplification, gel electrophoresis, PCR products purification were carried out in the DNA laboratory of the Natural History Museum, University of Oslo. 


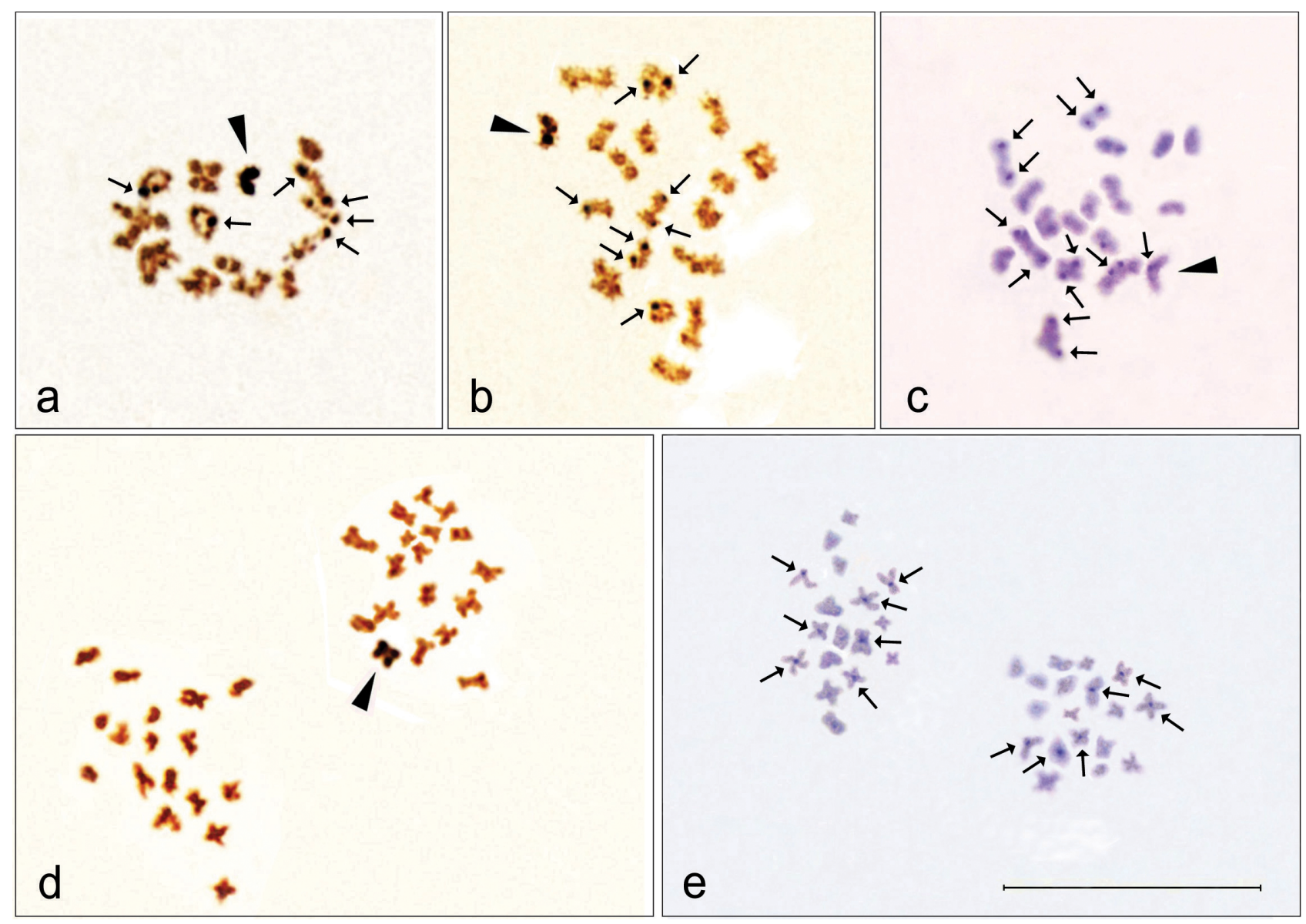

Fig. 2. Karyotype of males of Leptinotarsa decemlineata from Belarusian populations. a - early diakinesis; $\mathrm{b}$ - late diakinesis; $\mathrm{c}$ - metaphase I; d, e-metaphase II. Arrowheads indicate X-sex chromosome. a, b-Ag-banding, arrows indicate argentophilic signals (NORs); c, e-C-banding, arrows indicate C-blocks. Bar equals $10 \mu \mathrm{m}$.

All sequences obtained in this study were submitted to GenBank (accession numbers MW346681-MW346686 and MW348764-MW348766). Their accession numbers and specimen vouchers are presented in Table 2 . The voucher specimens and all DNA extracts were deposited in the Scientific Center of Zoology and Hydroecology, NAS RA.

\section{Samples and sequence alignment}

Nucleotide sequences obtained in this study were edited and aligned using BioEdit software (Hall, 1999). 27 additional DNA barcodes of $L$. decemlineata ( 3 from USA, 1 from Canada, 2 from Austria, 6 from Germany, 2 from Poland and 13 from Bashkortostan, Russia) were obtained from GenBank and added to the alignment. We edited the GenBank sequence JF889843 (Germany) by extracting its terminal part that was not properly aligned. DNA barcodes of L. haldemani, L. juncta and L. texana (11 samples) were also obtained from GenBank and added to the alignment as outgroups to root the trees (Table 2).

An additional alignment was created to study mitochondrial polymorphism in American populations. For this purpose, 82 haplotypes of the mitochondrial genome fragment that included the terminal part of the COI gene and the initial part of the COII gene were downloaded from GenBank (Crossley et al., 2017). Since this fragment does not overlap the standard DNA barcode, phylogenetic trees for it were built separately. The species Diabrotica undecimpunctata was used as an outgroup to root the trees.

\section{Phylogenetic tree construction}

The evolution model test for DNA substitutions was performed in MEGA X (Kumar et al., 2018). For the DNA barcode dataset, Tamura-Nei TN93+G was the optimal model. For the fragment that included the terminal part of the COI gene and the initial part of the COII gene, Tamura three-parameter $(\mathrm{T} 92+\mathrm{G})$ was the optimal model. Maximum Likelihood phylogenetic trees were constructed for the two datasets using the substitution models found. The standard nonparametric bootstrap (Felsenstein, 1985) (100 replicates) was used to evaluate the statistical nodal support of the trees.

The Bayesian phylogenetic analysis was performed using the program MrBayes v.3.2.7 (Ronquist et al., 2012). Two runs of $10,000,000$ generations with four chains (one cold and three heated) were performed for both datasets. The consensus of the obtained trees was visualized using FigTree v.1.4.4 (http://tree. bio.ed.ac.uk/software/figtree/).

\section{RESULTS}

\section{Chromosome analysis}

Nuclear divisions were found in CPB males of both Armenian and Belarusian populations. In females the karyotype could not be determined with certainty as divisions were rare and because the morphology of the chromosomes was unclear. 
Table 3. Nucleotides in four positions on the $\mathrm{CO}$ gene fragment differentiating the European DNA-barcodes from the four available Nearctic samples.

\begin{tabular}{|c|c|c|c|c|}
\hline$\frac{\text { Position }}{\text { Sequence }}$ & & & & $J 3$ \\
\hline L. decemlineata HQ605769 USA & $A$ & $A$ & $\mathrm{~T}$ & C \\
\hline L. decemlineata HQ605768 USA & A & A & $\mathrm{T}$ & C \\
\hline L. decemlineata AY165708 Canada & A & A & $\mathrm{T}$ & C \\
\hline L. decemlineata XM 023169376 USA & $A$ & $A$ & $\mathrm{~T}$ & C \\
\hline L. decemlineata KU915233 Germany & G & G & C & $\mathrm{T}$ \\
\hline L. decemlineata MW346681 Armenia & G & G & C & $\mathrm{T}$ \\
\hline L. decemlineata MW346685 Armenia & G & G & C & $\mathrm{T}$ \\
\hline L. decemlineata MW346683 Armenia & G & G & C & $\mathrm{T}$ \\
\hline L. decemlineata MW346686 Armenia & G & G & C & $\mathrm{T}$ \\
\hline L. decemlineata MW346682 Belarus & G & G & C & $\mathrm{T}$ \\
\hline L. decemlineata MW348764 Belarus & G & G & C & $\mathrm{T}$ \\
\hline L. decemlineata MW346684 Belarus & G & G & C & $\mathrm{T}$ \\
\hline L. decemlineata MW3487 & G & G & C & 1 \\
\hline MW348 & G & G & C & 1 \\
\hline a KU9146 & G & G & C & $\mathrm{T}$ \\
\hline KU9111 & G & G & C & $\mathrm{T}$ \\
\hline eata KU9099 & G & $G$ & C & $\mathrm{T}$ \\
\hline neata KU9071 & G & G & C & $\mathrm{T}$ \\
\hline lineata KM4391 & G & G & C & $\mathrm{T}$ \\
\hline lineata KM4394 & G & G & C & $\mathrm{T}$ \\
\hline L. decemlineata KM439249 Germany & G & $G$ & $c$ & $\mathrm{~T}$ \\
\hline L. decemlineata DQ649101 Russia Ba & G & $G$ & C & $\mathrm{T}$ \\
\hline mlineata DQ6490 & G & G & C & $\mathrm{T}$ \\
\hline a DQ6490 & G & G & C & $\mathrm{T}$ \\
\hline DQ127s & G & G & C & $\mathrm{T}$ \\
\hline L. de & G & G & C & $\mathrm{T}$ \\
\hline DQ649C & G & G & C & $\mathrm{T}$ \\
\hline L. $d \epsilon$ & G & G & C & $\mathrm{T}$ \\
\hline L. de & G & G & C & $\mathrm{T}$ \\
\hline a DQ6490 & G & G & C & $\mathrm{T}$ \\
\hline a DQ6490 & G & G & C & $\mathrm{T}$ \\
\hline L. decemlineata JF889843 Germany & G & G & C & G \\
\hline L. decemlineata DQ127907 Russia Bash & G & G & C & $\mathrm{T}$ \\
\hline L. decemlineata DQ011111 Russia Bas & G & G & C & - \\
\hline L. decemlineata DQ127908 Russia Bc & G & G & C & $\mathrm{T}$ \\
\hline L. decemlineata KM448111 Austria & G & G & C & $\mathrm{T}$ \\
\hline L. haldemani HM43 & A & A & $\mathrm{T}$ & G \\
\hline L. haldeman & A & A & $\mathrm{T}$ & G \\
\hline L. $I$ & - & A & $\mathrm{T}$ & $\mathrm{T}$ \\
\hline L. ha & A & A & $\mathrm{T}$ & $\mathrm{T}$ \\
\hline L. juncta KC25 & A & A & $\mathrm{T}$ & $\mathrm{T}$ \\
\hline 5770 USA & A & A & $\mathrm{T}$ & $\mathrm{T}$ \\
\hline L. juncta HQ605771 USA & A & A & $\mathrm{T}$ & $\mathrm{T}$ \\
\hline a HQ605774 USA & A & G & $\mathrm{T}$ & $\mathrm{T}$ \\
\hline a MK288007 South & A & G & $\mathrm{T}$ & $\mathrm{T}$ \\
\hline a MK288008 South Africa & A & G & $\mathrm{T}$ & $\mathrm{T}$ \\
\hline L. texana HQ605775 USA & A & G & $\mathrm{T}$ & $\mathrm{T}$ \\
\hline
\end{tabular}

Mitotic divisions were recorded only in beetles from Armenian populations. The male mitotic metaphase displayed 35 chromosomes including 17 autosomal pairs that constitute a decreasing size series and large meta- submetacentric X chromosome (Fig. 1a, b). All large and middle-sized chromosomal pairs were meta- and submetacentric, except for one acrocentric autosomal pair (AA2). The morphology of the small chromosomes was poorly visible, however, most likely, one autosomal pair (AA13) was acrocentric and the others biarmed.

Meiotic spermatocyte divisions were recorded in males from both Armenian and Belarusian populations. At diakinesis/metaphase I (MI) 17 autosomal bivalents and an un- paired meta- submetacentric $\mathrm{X}$ chromosome were observed (Figs 1c, d, e; 2a, b, c). The autosomal bivalents gradually decreased in size. At diakinesis and prometaphase there were two or three ring-shaped autosomal bivalents with two chiasmata, two cross-shaped bivalents with an interstitial chiasma and the remaining bivalents were rod-shaped and most likely had one terminal chiasma.

At metaphase II there were 17 and 18 chromosomes of which the majority were biarmed meta- and submetacentric. In each daughter cell, among the large meta- and submetacentric chromosomes one acrocentric chromosome was clearly visible, the morphology of the small chromosomes was unclear (Figs 1f, g; 2d, e).

At meiosis, Ag-banding revealed that the $\mathrm{X}$ chromosome was brightly homogenously argentophilic (Figs 1c, d, f; 2a, $\mathrm{b}, \mathrm{d})$. In addition, at diakinesis Ag-positive signals, probably NORs (the nucleolus organizer regions) were clearly visible on two ring-shaped and one rod-shaped bivalents; moreover, small and weak argentophilic signals were observed on two rod-shaped bivalents (Figs 1c; 2a, b). On the autosomal chromosomes at prometaphase-metaphase I and metaphase II there were no distinct Ag-positive signals.

The C-banding revealed a small amount of constitutive heterochromatin weakly visible in the pericentromeric regions of some chromosomes that did not form distinct blocks (Figs 1e, g; 2c, e). At prometaphase-metaphase I (Figs 1e, 2c), small pericentromeric block of C-heterochromatin was visible on the unpaired $\mathrm{X}$ chromosome, while at metaphase II (Figs 1g, 2e) it was unclear which of the large two-armed chromosomes was the $\mathrm{X}$ chromosome.

Thus, the karyotype of the males of Colorado potato beetle from Armenia and Belarus is $2 \mathrm{n}=35(34+\mathrm{X} 0), \mathrm{n}=$ $17 \mathrm{AA}+\mathrm{X} 0$. In beetles from all the populations studied, a pair of large acrocentric chromosomes was present.

\section{Comparison of the sequences and phylogenetic analyses}

Comparative analysis of the sequencing results revealed no nucleotide substitutions between samples from four Armenian and five Belarusian populations of L. decemlineata. Moreover, analysis of all available DNA barcodes revealed that this variant of the DNA barcode (herein called "European haplotype") was present in all the samples from Austria, Germany and Poland and in most (7 out of 13) samples from Bashkortostan (Russia). In 6 out of 13 Bashkortostan samples, few nucleotide substitutions are reported (Udalov \& Benkovskaya, 2010); however, in our opinion, it remains unclear whether these substitutions were real or sequencing errors. Examination of the DNA barcode alignment also revealed four transitions differentiating the European samples from the four American sequences (Table 3).

Bayesian Inference (BI) and Maximum Likelihood (ML) phylogenetic analyses of the Leptinotarsa DNA barcodes revealed the topology shown in Fig. 3.

In both BI and ML trees, the sequence HQ605769 from North Dakota, USA appeared as a sister to the clade that included all the European sequences (Fig. 3). Together, the North Dakota sequence and the European sequences 


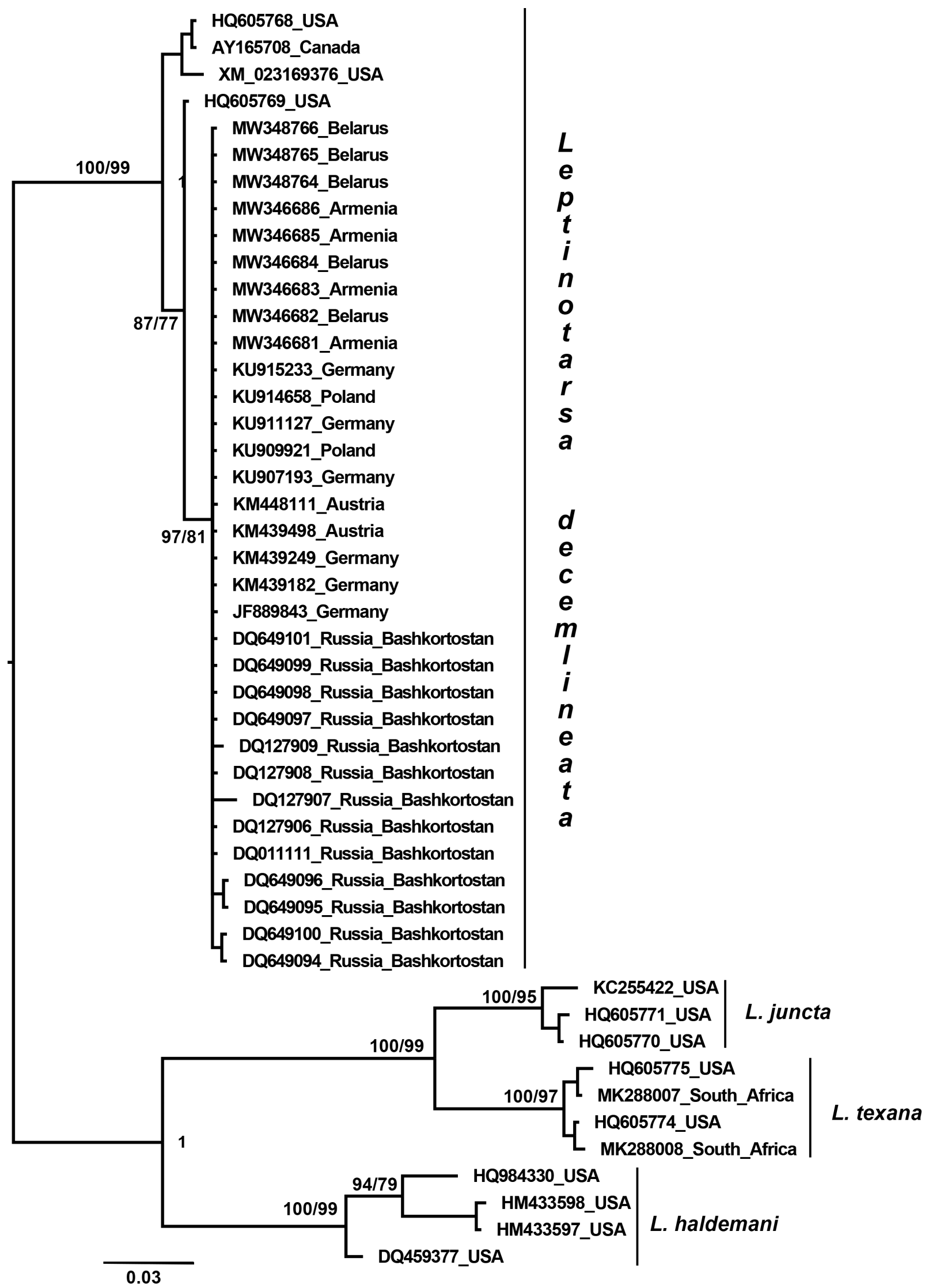

Fig. 3. Bayesian phylogenetic tree based on Leptinotarsa DNA barcodes. Maximum likelihood analysis revealed the same topology. The GenBank accession number and country of origin are listed for every sequence. Bayesian posterior probability for BI/Bootstrap value support for ML are indicated at nodes. 


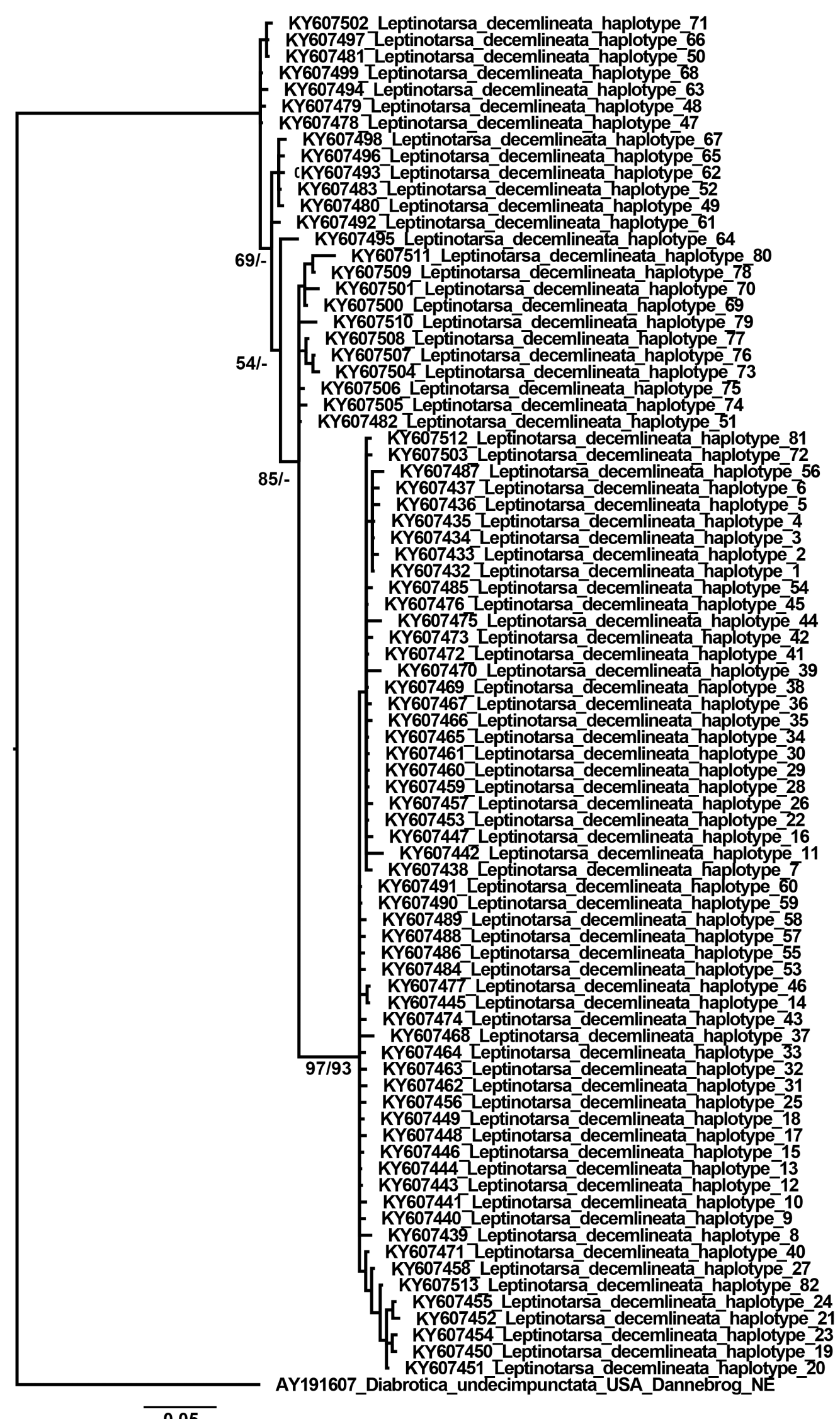

Fig. 4. Bayesian phylogenetic tree based on the North American haplotypes of the mitochondrial genome fragment that included the terminal part of the $\mathrm{COI}$ gene and initial part of the COIl gene. The sequences of the North American Leptinotarsa decemlineata samples published by Crossley et al., 2017 and extracted from the GenBank were analysed. For every sequence the GenBank accession number and haplotype number are listed. Bayesian posterior probability for BI/Bootstrap value support for ML are indicated at nodes. Sign "-" at the node support means that the clade was not revealed by the ML analysis. 
formed a sister clade to the clade consisting of the other three North American CPB sequences. The samples from three other species of Leptinotarsa (L. haldemani, L. juncta and L. texana) formed three separate clades, of which $L$. juncta and L. texana were sister clades, while L. haldemani was another separate clade. In addition, the sequence HQ984330 of the specimen mentioned in GenBank as Leptinotarsa $\mathrm{sp}$. belonged to the last clade and, therefore, to the same species.

Additional phylogenetic analyses were conducted to study mitochondrial polymorphism in American populations. For this purpose, 82 haplotypes of the mitochondrial genome fragment that included the terminal part of the $C O I$ gene and the initial part of the COII gene were used. BI and $\mathrm{ML}$ analyses of these haplotypes revealed the topology shown in Fig. 4. In contrast to European samples (Fig. 3), these analyses showed a high level of mitochondrial polymorphism in North American populations and revealed several major haplogroups (Fig. 4), with a divergence level between them of up to $4 \%$.

\section{DISCUSSION}

There are more than 40 species in the genus Leptinotarsa (Jacques, 1988). Currently, there are published karyotypes for only 15 species of Leptinotarsa (for references, see Petitpierre et al., 1988, who mention 16 species, but based on the karyology of $L$. signaticollis Jacoby, 1883 published by Wieman, 1910 and Hsiao \& Hsiao, 1983, was synonymised with L. undecemlineata (Stål, 1858) (Jacques, 1988)).

The haploid karyotype $\mathrm{n} \hat{\sigma}=17 \mathrm{AA}+\mathrm{X} 0$ is the modal chromosome number for the genus Leptinotarsa and recorded in 13 species (Hsiao \& Hsiao, 1983; Petitpierre et al., 1988). Lower chromosome numbers are reported in two species: $\mathrm{n}{ }^{\lambda}=16 \mathrm{AA}+\mathrm{X} 0$ in $L$. undecemlineata (as $L$. undecimlineata in Virkki, 1964; Hsiao \& Hsiao, 1983) and $\mathrm{n} \widehat{O}=11 \mathrm{AA}+\mathrm{X} 0$ in L. belti Stål, 1858 (as Polygramma belti in Virkki, 1964). The karyotype with the lowest number of $n=12$ could represent the plesiomorphic condition and is ancestral for the subtribe Doryphorina (Petitpierre, 2011).

According to T.H. Hsiao (1985), the Colorado potato beetle is a chromosomally polymorphic species in North America. There are three chromosomal "races": (1) the metacentric "race", in which all autosomes are metacentric (Mexico, USA), (2) the acrocentric "race", derived from the metacentric "race" by the pericentric inversion in the second pair of autosomes (USA, Europe) and (3) the heterozygous meta-acrocentric "race" (USA, Canada). More recent studies revealed a large acrocentric chromosome pair in the chromosomes of a population from Canena in Spain, thus, confirming the presence of the acrocentric "race" of CPB in Europe (Lorite et al., 2013).

Our studies did not reveal chromosomal polymorphism in Armenian and Belarusian populations of CPB. The large autosomal acrocentric pair was found in the karyotypes of all the populations of $L$. decemlineata studied. Therefore, we assume that both Armenian and Belarusian populations of CPB belong to the acrocentric "race", which according to literature data, is peculiar to European populations.

Up till now, karyological studies on CPB were carried out using mainly conventional staining techniques. In the present paper, Ag-banding was used to study the karyotype of the Colorado potato beetle for the first time. This revealed that the $\mathrm{X}$ chromosome was homogenously argentophilic during the different stages of meiosis in all the populations studied, which is most likely due to the presence of an argentophilic substance (proteins). At diakinesis there were clearly visible argentophilic signals (probably NORs) located on some autosomal bivalents: the two ringshaped and one rod-shaped bivalents. Weak argentophilic signals were also detected on a few bivalents.

Baus Lončar et al. (2005) report for the first time the Cbanding staining of the chromosomes of L. decemlineata, which is confirmed by our study in which the chromosomes had a small amount of constitutive heterochromatin located pericentromerically. This observation is consistent with the data for other beetles. It is known that in most species of the order Coleoptera large C-blocks on chromosomes are uncommon and only recorded in a few species (for references see Rożek et al., 2004; Karagyan et al., 2012).

In the current study, analysis of the DNA barcode fragment of the $C O I$ gene revealed lack of interpopulation variability in all samples of CPB collected from different locations in Armenia and Belarus. Thus, there is only a single DNA barcode haplotype. Moreover, analysis of sequences from Austria, Germany and Poland available in the literature (Hendrich et al., 2015; Rulik et al., 2017) indicate that this DNA barcode haplotype ("European haplotype") is the only variant known from Western Europe. A more complicated situation is found in Bashkortostan (Russia) where the European haplotype is present in 7 of 13 studied samples (Udalov \& Benkovskaya, 2010). In 6 out of 13 Bashkortostan samples, there are few nucleotide substitutions (Udalov \& Benkovskaya, 2010); however, in our opinion, it is unclear whether these substitutions are real or sequencing errors. Anyway, the European haplotype is the only or the predominant one in all populations of the Old World studied. Therefore, we hypothesize that the European haplotype is the ancestral state for all populations of the Old World and inherited from the New World invaders who colonized Europe 100 years ago.

In contrast to Europe, the DNA analysis of American samples, both carried out earlier (Izzo et al., 2018) and in the current study, reveal an extremely high level of polymorphism. It should be noted, however, that the analysis of American samples is based on the other fragment of the mitochondrial genome, which makes it difficult to directly compare the American and European data and prevents the phylogeographic analysis of the entire dataset (America + Europe). For this reason, we cannot identify the North American population that was the ancestor of the European lineage of the Colorado potato beetle. Nevertheless, we believe that the population-ancestor will be found in North America in the near future and will shed light on the origin of the populations of this dangerous pest in Eurasia. 
ACKNOWLEDGEMENTS. The present study was supported by the RA MES State Committee of Science and RB State Committee of Science and Technology within the frame work of the joint research projects ArmBel-Ap18 1f-5 and Б18АРМГ-002. V.A. Lukhtanov was supported by the state research project AAAA-A19-119020790106-0 (molecular analysis of New World samples) and by grant no. 19-14-00202 from the Russian Science Foundation to the Zoological Institute of the Russian Academy of Sciences (molecular analysis of New World samples). We would like to express our gratitude to V. Gusarov (Natural History Museum, University of Oslo) for the opportunity of conducting molecular research within the framework of the project "EntoMol", supported by the Eurasia Programme 2017-2019 of the Norwegian Agency for International Cooperation and Quality Enhancement in Higher Education (Diku) (Project CPEALT-2016/10140). We are thankful to M. Kalashian (Scientific Center of Zoology and Hydroecology, NAS RA) whose constructive criticism, valuable comments and suggestions helped improve our manuscript.

\section{REFERENCES}

Alyokhin A. 2009: Colorado potato beetle management on potatoes: current challenges and future prospects. - Fruit Veg. Cereal Sci. Biotech. 3 (Special Issue 1): 10-19.

Azeredo-Espin A.M.L., Schroder R.F.W., Huettel M.D. \& ShepPARD W.S. 1991: Mitochondrial DNA variation in geographic populations of Colorado potato beetle, Leptinotarsa decemlineata (Coleoptera, Chrisomelidae). - Experientia 47: 483-485.

Azeredo-Espin A.M.L., Schroder R.F.W., Roderick G.K. \& SHEPPARD W.S. 1996: Intraspecific mitochondrial DNA variation in the Colorado potato beetle, Leptinotarsa decemlineata (Coleoptera: Chrysomelidae). — Biochem. Genet. 34: 253 268.

Barton N.H. \& Charlesworth B. 1984: Genetic revolutions, founder effects, and speciation. - Annu. Rev. Ecol. Syst. 15: $133-164$.

Baus Lončar M., Paić F. \& Ugarković Đ. 2005: Molecular cytogenetic study of heterochromatin in some coleopteran insects. - Entomol. Croat. 9(1-2): 47-56.

Boiteau G. 1994: Genetics of the Colorado potato beetles, Leptinotarsa decemlineata (Say). In Jolivet P.H., Cox M.L. \& Petitpierre (eds): Novel Aspects of the Biology of Chrysomelidae. Kluwer, Dordrecht, pp. 231-236.

BrechKo E.V., Elisovetskaya D.S., Nastas T.N., VoitKa D.V. \& YANKOUSKAYA A.N. 2016: Formation of phenotypic structure of Colorado potato beetle (Leptinotarsa decemlineata Say) populations under ecological stress conditions. - Proc. Nat. Acad. Sci. Belarus (Agrar. Ser.) 4: 79-89 [in Russian].

Capinera J.L. 2001: Handbook of Vegetable Pests. Academic Press, San Diego, 729 pp.

Cohen Z.P., Brevik K., Chen Y.H., Hawthorne D.J., Weibel B.D. \& SCHoville S.D. 2021: Elevated rates of positive selection drive the evolution of pestiferousness in the Colorado potato beetle (Leptinotarsa decemlineata, Say). - Mol. Ecol. 30: 237-254.

CONGER A.D. \& FAIRChILD L.M. 1953: A quick-freeze method for making smear slides permanent. — Stain Technol. 28: 289293.

Crossley M.S., Chen Y.C., Groves R.L. \& Schoville S.D. 2017: Landscape genomics of Colorado potato beetle provides evidence of polygenic adaptation to insecticides. - Mol. Ecol. 26: 6284-6300.

De Wilde J. \& Hsiao T.H. 1981: Geographic diversity of the Colorado potato beetle and its infestation in Eurasia. In Lashomb
J.H. \& Casagrande R.A. (eds): Advances in Potato Pest Management. Hutchinson Ross, Stroudsburg, PA, pp. 47-68.

Dlugosch K.M. \& Parker I.M. 2008: Founding events in species invasions: genetic variation, adaptive evolution, and the role of multiple introductions. - Mol. Ecol. 17: 431-449.

Fasulati S.R. 1993: Polymorphism, environmental groups, and microevolution of Colorado potato beetle Leptinotarsa decemlineata Say (Coleoptera, Chrysomelidae). In: Species and Its Productivity in the Range. Gidrometeoizdat, St. Petersburg, pp. 260-262 [in Russian].

Felsenstein J. 1985: Confidence limits on phylogenies: an approach using the bootstrap. - Evolution 39: 783-791.

Folmer O., Black M., Hoeh W., Lutz R. \& Vrijenhoek R. 1994: DNA primers for amplification of mitochondrial cytochrome $c$ oxidase subunit I from diverse metazoan invertebrates. - Mol. Mar. Biol. Biotechnol. 3: 294-299.

GRAPPUTO A. 2006: Development and characterization of microsatellite markers in the Colorado potato beetle, Leptinotarsa decemlineata. - Mol. Ecol. Notes 6: 1177-1179.

Grapputo A., Boman S., Lindström L., Lyytinen A. \& Mappes J. 2005: The voyage of an invasive species across continents: genetic diversity of North American and European Colorado potato beetle populations. - Mol. Ecol. 14: 4207-4219.

Greenstone M.H., Rowley D.L., Weber D.C., Payton M.E. \& HaWthorne D.J. 2007: Feeding mode and prey detectability half-lives in molecular gut-content analysis: an example with two predators of the Colorado potato beetle. - Bull. Entomol. Res. 97: 201-209.

GuÉNIN H.A. \& SCHERLER M. 1951: La formule chromosomiale du doryphore Leptinotarsa decemlineata Stal. - Rev. Suisse Zool. 58: 359-370.

Hall T.A. 1999: BioEdit: a user-friendly biological sequence alignment editor and analysis program for Window 95/98/NT. - Nucl. Acids Symp. Ser. 41: 95-98.

Hawthorne D.J. 2001: AFLP-Based genetic linkage map of the Colorado potato beetle Leptinotarsa decemlineata: sex chromosomes and a pyrethroid-resistance candidate gene. - Genetics 158: 695-700.

Hebert P.D.N., Cywinska A., Ball S.L. \& deWaArd J.R. 2003: Biological identifications through DNA barcodes. - Proc. $R$. Soc. Lond. (B) 270: 313-321.

Hendrich L., Morinière J., Haszprunar G., Hebert P.D.N., HausmanN A., KöHler F. \& Balke M. 2015: A comprehensive DNA barcode database for Central European beetles with a focus on Germany: adding more than 3500 identified species to BOLD. - Mol. Ecol. Resour. 15: 795-818.

Holm A.K., Elameen A., Oliver B.W., Brandseter L.O., FløisTAD I.S. \& BRURBERG M.B. 2018: Low genetic variation of invasive Fallopia spp. in their northernmost European distribution range. - Ecol. Evol. 8: 755-764.

Howell W.M. \& Black D.A. 1980: Controlled silver-staining of nucleolus organizer regions with a protective colloidal developer: a 1-srep method. - Experientia 36: 1014-1015.

HsiaO T.H. 1985: Ecophysiological and genetic aspects of geographic variations of the Colorado potato beetles. In Ferro D.N. \& Voss R.H. (eds): Proceedings of the Symposium on the Colorado Potato Beetle. XVIIth International Congress of Entomology. Mass. Agr. Exp. Stat. Res. Bull. 704, University of Massachusetts, Amherst, pp. 63-77.

Hsiao C. \& HSIAO T.H. 1982: Inheritance of three autosomal mutations in the Colorado potato beetle Leptinotarsa decemlineata (Coleoptera: Chrysomelidae). - Can. J. Genet. Cytol. 24: 681-686. 
Hsiao T.H. \& Hsiao C. 1983: Chromosomal analysis of Leptinotarsa decemlineata and Labidomera species (Coleoptera: Chrysomelidae). - Genetica 60: 139-150.

Izzo V.M., Chen Y.H., Schoville S.D., Wang C. \& Hawthorne D.J. 2018: Origin of pest lineages of the Colorado potato beetle (Coleoptera: Chrysomelidae). - J. Econ. Entomol. 111: 868-878.

JACOBSON J.W. \& HsiaO T.H. 1983: Isozyme variation between geographic populations of the Colorado potato beetle, Leptinotarsa decemlineata (Coleoptera: Chrysomelidae). - Ann. Entomol. Soc. Am. 76: 162-166.

JACQues R.L. 1988: The Potato Beetles: The Genus Leptinotarsa in North America (Coleoptera, Chrysomelidae). Flora and Fauna Handbook, Vol. 3. Brill, New York, 144 pp.

Jolivet P. 1991: Le doryphore menace 1'Asie Leptinotarsa decemlineata Say 1824 (Coleoptera: Chrysomelidae). — Entomologiste 47: 29-48.

Karagyan G., Lachowska D. \& Kalashian M. 2012: Karyotype analysis of four jewel-beetle species (Coleoptera, Buprestidae) detected by standard staining, C-banding, AgNOR-banding and CMA3/DAPI staining. - Comp. Cytogen. 6: 183-197.

Kress W.J., García-Robledo C., Uriarte M. \& Erickson D.L. 2015: DNA barcodes for ecology, evolution, and conservation. - Trends Ecol. Evol. 30: 25-35.

Kumar S., Stecher G., Li M., Knyaz C. \& Tamura K. 2018: MEGA X: Molecular evolutionary genetics analysis across computing platforms. - Mol. Biol. Evol. 35: 1547-1549.

LiU N., Li Y. \& Zhang R. 2012: Invasion of Colorado potato beetle, Leptinotarsa decemlineata, in China: dispersal, occurrence, and economic impact. - Entomol. Exp. Appl. 143: 207-217.

Lorite P., Torres M.I. \& Palomeque T. 2013: Characterization of two unrelated satellite DNA families in the Colorado potato beetle Leptinotarsa decemlineata (Coleoptera, Chrysomelidae). - Bull. Entomol. Res. 103: 538-546.

Markovets A.F. 1950: Colorado Potato Beetle - Most Dangerous Pest of Crops of Potato. Academy of Sciences of Belorussian SSR, Minsk, 15 pp. [in Russian].

Nalbandyan A.V. 1984: Regularities of the Population Dynamics of the Colorado Potato Beetle and Rational Methods of Fighting it in the Northeastern Zone of the Armenian SSR. PhD thesis, Armenian Scientific-Research Institute of Plant Protection, Yerevan, 139 pp. [in Russian].

Nie R.-E., Breeschoten T., Timmermans M.J.T.N., Nadein K., Xue H.-J., Bai M., Huang Y., Yang X.-K. \& Vogler A.P. 2018: The phylogeny of Galerucinae (Coleoptera: Chrysomelidae) and the performance of mitochondrial genomes in phylogenetic inference compared to nuclear rRNA genes. - Cladistics 34: 113-130.

Petitpierre E. 2011: Cytogenetics, cytotaxonomy and chromosomal evolution of Chrysomelinae revisited (Coleoptera, Chrysomelidae). - ZooKeys 157: 67-79.

Petitpierre E., Segarra C., Yadav J.S. \& VirkKi N. 1988: Chromosome numbers and meioformulae of Chrysomelidae. In Jolivet P., Petitpierre E. \& Hsiao T.H. (eds): Biology of Chrysomelidae. Kluwer, Dordrecht, pp. 161-186.

Przybylska A., Budziszewska M., Klejdysz T., Nawrot J. \& OBRĘPALSKA-STĘPLOWSKA A. 2014: High stability of a mitochondrial genetic marker $m t C O I I$ in Polish Colorado potato beetle populations. - Am. J. Potato Res. 91: 720-725.

Roman J. \& Darling J.A. 2007: Paradox lost: genetic diversity and the success of aquatic invasions. - Trends Ecol. Evol. 22: $454-464$.
Ronquist F., Teslenko M., van der Mark P., Ayres D.L., Darling A., Höhna S., Larget B., Liu L., Suchard M.A. \& HuelsenBECK J.P. 2012: MrBayes 3.2: efficient Bayesian phylogenetic inference and model choice across a large model space. — Syst. Biol. 61: 539-542.

Roż̇K M. 2000: The C-banding technique for Coleoptera (Insecta). - Folia Biol. (Kraków) 48: 29-31.

Rożek M., Lachowska D., Petitpierre E. \& Holecová M. 2004: C-bands on chromosomes of 32 beetle species (Coleoptera: Elateridae, Cantharidae, Oedemeridae, Cerambycidae, Chrysomelidae and Curculionidae). - Hereditas 140: 1-10.

Rulik B., Eberle J., von der Mark L., Thormann J., Jung M., KöHler F., Apfel W., Weigel A., Kopetz A., Köhler J., et AL. 2017: Using taxonomic consistency with semi-automated data pre-processing for high quality DNA barcodes. - Methods Ecol. Evol. 8: 1878-1887.

Sidorenko A.P. \& BerezovsKa O.P. 2002: Genetic structure of populations of the Colorado potato beetle Leptinotarsa decemlineata (Coleoptera: Chrysomelidae). — Russ. J. Genet. 38: $1256-1261$

Sidorenko A.P., Berezovskaya O.P. \& Sozinov A.A. 2000: The assessment of genetic polymorphism in populations of Colorado potato beetle Leptinotarsa decemlineata (Say) using RAPD markers. - Russ. J. Genet. 36: 526-532.

Sмiтh S.G. 1953: Chromosome numbers of Coleoptera. - Heredity 7 : $31-48$.

Stevens N.M. 1906: Studies in Spermatogenesis, Part II. Carnegie Institution of Washington, Washington D.C, pp. 33-74.

Udalov M.B. \& Benkovskaya G.V. 2010: Polymorphism coxI gene of Colorado potato beetle in South Ural populations. Resistant Pest Manag. Newslett. 19(2): 29-32.

Udalov M.B. \& Benkovskaya G.V. 2011: Population genetics of the Colorado potato beetle: From genotype to phenotype. Russ. J. Genet. Appl. Res. 1: 321-333.

Ushatinskaya R.S. (ed.). 1981: Colorado Potato Beetle, Leptinotarsa decemlineata Say. Phylogeny, Morphology, Physiology, Ecology, Adaptation, Natural Enemies. Nauka, Moscow, 377 pp. [in Russian].

VIRKKI N. 1964: On the cytology of some Neotropical Chrysomelids. - Ann. Acad. Sci. Fenn. (A4, Biol.) 75: 1-25.

WIEMAN H.L. 1910: A study of the germ cells of Leptinotarsa signaticollis. - J. Morphol. 21: 135-216.

YANG F., GuO J., Liu N. \& Zhang R. 2020: Genetic structure of the invasive Colorado potato beetle Leptinotarsa decemlineata populations in China. - J. Integ. Agr. 19: 350-359.

Yocum G.D., Toutges M.J., Roehrdanz R.L. \& Dihle P.J. 2011: Insertion of miniature subterminal inverted repeat-like elements in diapause-regulated genes in the Colorado potato beetle, Leptinotarsa decemlineata (Coleoptera: Chrysomelidae). - Eur. J. Entomol. 108: 197-203.

Zehnder G.W., Sandall L., Tisler A.M. \& Powers T.O. 1992: Mitochondrial DNA diversity among 17 geographic populations of Leptinotarsa decemlineata (Coleoptera: Chrysomelidae). - Ann. Entomol. Soc. Am. 85: 234-240.

Zhang J.J., Yang J., Li Y.C., Liu N. \& Zhang R.Z. 2013: Genetic relationships of introduced Colorado potato beetle Leptinotarsa decemlineata populations in Xinjiang, China. _ Insect Sci. 20: $643-654$.

Received April 14, 2021; revised and accepted October 12, 2021 Published online November 12, 2021 